\title{
Formation Characteristics of $\mathrm{N}$-Nitrosodimethylamine during Chloramines of PolyDADMAC
}

\author{
Lahua Jin, Chen Ge, Jiayi Wang \\ School of Environment, Jinan University, Guangzhou, China \\ Email: tlhjin@jnu.edu.cn,2471067464@qq.com,382266873@qq.com
}

How to cite this paper: Jin, L.H., Ge, C. and Wang, J.Y. (2019) Formation Characteristics of N-Nitrosodimethylamine during Chloramines of PolyDADMAC. Journal of Environmental Protection, 10, 1602-1611.

https://doi.org/10.4236/jep.2019.1012096

Received: October 25, 2019

Accepted: December 14, 2019

Published: December 17, 2019

Copyright $\odot 2019$ by author(s) and Scientific Research Publishing Inc. This work is licensed under the Creative Commons Attribution International License (CC BY 4.0).

http://creativecommons.org/licenses/by/4.0/

\begin{abstract}
Interactions of chloramine with organic nitrogen compounds during purification of water for drinking may generate carcinogenic $\mathrm{N}$-nitrosodimethylamine (NDMA) as byproduct, and it has been found that cationic amine-based water treatment polymers may be one of the important precursors of NDMA. We have analyzed experimentally the influence rule of NDMA formation during chlorination and disinfection, in order to provide technical support for reducing or even avoiding the formation of NDMA. The formation characteristics of nitrosamines during the chlorination of poly-diallyldimethylammonium chloride (polyDADMAC) have been studied during our experiments. The results show that the type of chlorinating agent is crucial for the generation of NDMA; if $\mathrm{pH}=7$, NDMA has the great potential formation; the NDMA potential formation increases with temperature. The yield of NDMA will be higher as the concentration of monochloramine is 1.5 to 2.5 times of the precursor; the variation of polymer with reaction time can explain the concentration of NDMA in terminal water of pipe network is higher than that in drinking water.
\end{abstract}

\section{Keywords}

N-Nitrosodimethylamine, Poly-Diallyldimethylammonium Chloride, Monochloramine, Coconut Charcoal SPE Tube

\section{Introduction}

In order to reduce the yield of disinfection by-products (DBPs), the process of chlorination during the production of drinking water has been replaced with disinfectants such as chlorine dioxide, chloramines and ozone, but the consequent problem is that nitrogen-containing disinfection by-products (N-DBPs) 
are often discovered. There are nine N-Nitrosamines frequently detected in drinking water, i.e., N-nitrosodimethylamine (NDMA), N-nitrosomethylethylamine (NMEA), N-nitrosodiethylamine (NDEA), N-nitrosodinpropylamine (NDPA), $\mathrm{N}$-Nitrosodibutylamine (NDBA), N-nitrosomethoxine (NMor),

$\mathrm{N}$-nitrosopyrrolidine (NPyr), N-nitrosopiperidine (NPip) and

$\mathrm{N}$-nitrosodiphenylamine (NDPhA). NDMA is the most typical representative of $\mathrm{N}$-Nitrosamines. It has been found that the concentration of N-Nitrosamines in drinking water pipe network in mega cities of China is about 5 - $50 \mathrm{ng} / \mathrm{L}$ [1]. Although the concentration of N-Nitrosamines in drinking water is only a few, it has higher genotoxicity, cytotoxicity, and potential carcinogenicity than traditional carbonaceous DBPs [2].

Due to the frequent detection and obvious health risk of N-Nitrosamines in drinking water, a lot of experimental researches and theoretical analyses on how to control the yield of N-Nitrosamines in drinking water have been made in recent years, and some valuable results have been obtained, such as the reaction of amine-containing compounds (N-Nitrosamines precursors) with chloramines (mainly dichloramines) in water treatment favors NDMA formation [3] [4], the precursors of N-Nitrosamines derive from effluent scouring of surface water, tertiary amines, fungicides containing secondary amine moieties, quaternary ammonium chemicals, anion exchange resins, amine-based organic coagulants, and lower \& middle molecular weight Natural organic matter (NOM) [5]. In the precursor of NDMA, amine-based polymers water treatment polymers have been got considerable attention, which are commonly used as coagulants or flocculants in water and wastewater treatment systems. Mechanisms of NDMA formation from free chlorine, chloramination or ozone of several coagulants/flocculant polymes (amine-based polymers) most commonly used in potable water treatment, have been also reported [6] [7] [8]. However, there are no reports in the literature about the specific influencing factors and the formation rules of flocculant polymer in the process of chlorination.

In order to find out the formation characteristics of $\mathrm{N}$-nitrosodimethylamine during Chloramines of PolyDADMAC for reducing the risk of NDMA, we took polyDADMAC as Nitrosamine precursors, in which polyDADMAC is frequently applied as coagulant during the process of water purification, and made a serial of chlorinating experiments to reveal the effect of chlorinating agent type, $\mathrm{pH}$ value, reaction temperature, precursor initial concentration and reaction time on the formation of NDMA during the chlorination of amine-based water treatment polymers polyDADMAC.

\section{Materials and Methods}

\section{Materials and Instruments}

The main instruments used in the experiment were as follows: GC/MS-QP2010 Ultra Gas Chromatography-Mass Spectrometer (Shimadzu Corporation); PTA-5 type chromatography column (Supelco USA): $30 \mathrm{~m} \times 0.25 \mathrm{~mm} \times 0.5 \mu \mathrm{m}$; Cross-contamination solid phase extraction device (Supelco, USA); R-300 rotary 
evaporator (BUCHI, Switzerland); SPE cartridge (2 g coconut charcoal cartridge, $6 \mathrm{~mL}$, Supelco, USA); MILLI-Q A10 ultrapure water Machine (Millipore, USA).

The main materials and reagents used in the experiment were: PolyDADMAC (molecular weight 200,000 - 350,000, aqueous solution of $20 \mathrm{wt} . \%, 250-500 \mathrm{cP}$ $\left(25^{\circ} \mathrm{C}\right)$, Macklingent Company); mixed standard solution of $9 \mathrm{~N}$-nitrosamines NAs, $2000 \mu \mathrm{g} / \mathrm{L}$, dissolved in dichloromethane, (Supelco, USA); deuterated $\mathrm{N}$-nitrosodimethylamine (NDMA- $\mathrm{d}_{6}, 1000 \mu \mathrm{g} / \mathrm{mL}$, dissolved in methanol, O2Si, USA) and deuterated N-Nitrosodinpropylamine (NDPA- $\mathrm{d}_{14}, 1000 \mu \mathrm{g} / \mathrm{L}$ in methanol, O2Si USA); methylene chloride City Keke a Division Miou Chemical Reagent Co, Ltd.); anhydrous sodium sulfate; ascorbic acid; sodium hypochlorite (analytical grade, Tianjin Damao Chemical Reagent Factory); ammonium chloride (Tianjin Fu Chen Chemical Reagent Factory); deionized water.

\section{Experiment Methods}

\subsection{NDMA Chlorination Method}

All glassware was washed with deionized water and baked at $450^{\circ} \mathrm{C}$ for $4 \mathrm{~h}$ before use. All reactions were conducted in a $1 \mathrm{~L}$ amber borosilicate bottle at $24.0^{\circ} \mathrm{C} \pm 1.0^{\circ} \mathrm{C}$. The samples were held for $24 \mathrm{~h}$ in a dark place. With deionized water to prepare the polymer active ingredient $500 \mathrm{mg} / \mathrm{L}$ of stock solutions, the experiment was diluted to $2-10 \mathrm{mg} / \mathrm{L}$ of the reaction solution, adding an appropriate amount of $0.2 \mathrm{M}$ phosphate buffer, and adjusted to $\mathrm{pH}=7 \pm 0.2$. In order to simplify the interpretation of the results and avoid the substrate with sodium hypochlorite reaction, In experiment, we used preformed monochloramine (The molar ratio of $\mathrm{Cl} / \mathrm{N}$ is 0.7 ) to add to polyDADMAC-containing solution, instead of adding ammonia first then adding sodium hypochlorite in solution to form monochloramine. Determination of residual chlorine after the chlorination reaction was completed, adding an appropriate amount of ascorbic acid to quench excess chlorine. All experiments were done in triplicate.

\subsection{Monochloramine Preparation and Analysis Methods}

Approximately $1800 \mathrm{mg} \mathrm{Cl} / \mathrm{L}$ of monochloramine stock solution $(\mathrm{Cl} / \mathrm{N}$ molar ratio of 0.7 ) was freshly prepared for each experiment, adding about 3500 $\mathrm{mg} / \mathrm{L}$ sodium hypochlorite slowly into $1000 \mathrm{mg} / \mathrm{L}$ ammonium chloride solution of $\mathrm{pH}=9$. The $\mathrm{pH}$ of monochloramine was maintained above 9.0 using $10 \mathrm{mM}$ bicarbonate or phosphate buffer during the reaction to minimize disproportionation to dichloramine. This preformed monochloramine solution was aged in the dark for one hour and used for experiments within one day. The exact concentrations monochloramine were determined for every sample by the $\mathrm{N}, \mathrm{N}$-diethyl-p-phenylenediamine-ferrous ammonium sulfate (DPD-FAS) titration method specified in the Standard Methods.

\subsection{Nitrosamine Analysis Methods}

Nine nitrosamines in water were extracted by solid phase extraction (SPE) and 
quantitative analysis by gas chromatography-mass spectrometry (GC-MS) [9]. During our experiments, GC-MS conditions are as follows: the ion source is EI source, the electron energy is $-70 \mathrm{ev}$, the carrier gas is high purity helium, and the sample is injected $1 \mu \mathrm{L}$ without splitting, the temperature of the sample inlet is $250^{\circ} \mathrm{C}$, the temperature of the transmission line is $280^{\circ} \mathrm{C}$, the temperature of the ion source is $210^{\circ} \mathrm{C}$, and the carrier gas flow rate is $2.0 \mathrm{~mL} / \mathrm{min}$.

\section{Results and Analyses}

\subsection{Effect of Types of Chlorinating Agents on NDMA Formation}

At $24.0^{\circ} \mathrm{C} \pm 1.0^{\circ} \mathrm{C}, \mathrm{pH}=7$, diluting the stock solution with deionized water to prepare a $1 \mathrm{~L}$ water sample with a polymer active ingredient of $10 \mathrm{mg} / \mathrm{L}$, Separately chlorinated $24 \mathrm{~h}$ with $10 \mathrm{mg} / \mathrm{L}$ monochloramine and $10 \mathrm{mg} / \mathrm{L}$ sodium hypochlorite in the dark. The result is shown in Figure 1.

From Figure 1, it can be seen that under the same conditions, polyDADMAC and sodium hypochloritechlorinated for $24 \mathrm{~h}$ to generate NDMA only $50 \mathrm{ng} / \mathrm{L}$, however monochloramine for chlorination generated $1000 \mathrm{ng} / \mathrm{L}$ of NDMA, which is much higher than that generated by sodium hypochlorite chlorinated. Meanwhile the concentration of NDMA generated by sodium hypochlorite is $5 \%$ of monochloramine generated. Therefore, it is crucial to choose of chlorinating agent for the formation of NDMA. In addition, although the concentration of NDMA formed by sodium hypochlorite is low, it also has health risks in drinking water. Therefore, the precursor substances should be removed as much as possible before chlorination.

\subsection{Effect of pH on NDMA Formation}

At a temperature of $24.0^{\circ} \mathrm{C} \pm 1.0^{\circ} \mathrm{C}, 1 \mathrm{~L}$ of polymer active ingredient of $5 \mathrm{mg} / \mathrm{L}$ and react with $10 \mathrm{mg} / \mathrm{L}$ of monochloramine in the dark for 24 hours to determine residual chlorine in the water. The result is shown in Figure 2. The effect of $\mathrm{pH}$ on NDMA formation in chlorination was shown in Figure 3.

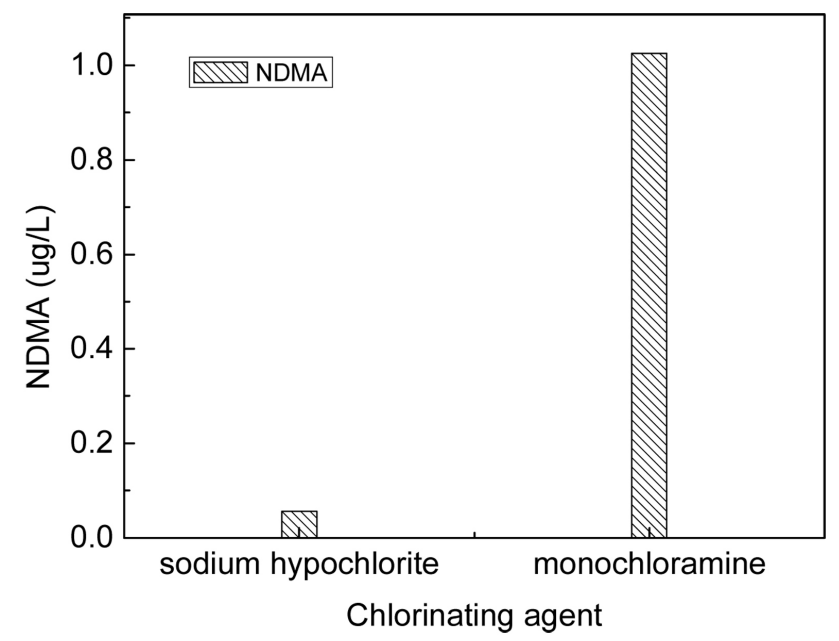

Figure 1. Effect of chlorinating agents on NDMA formation. 


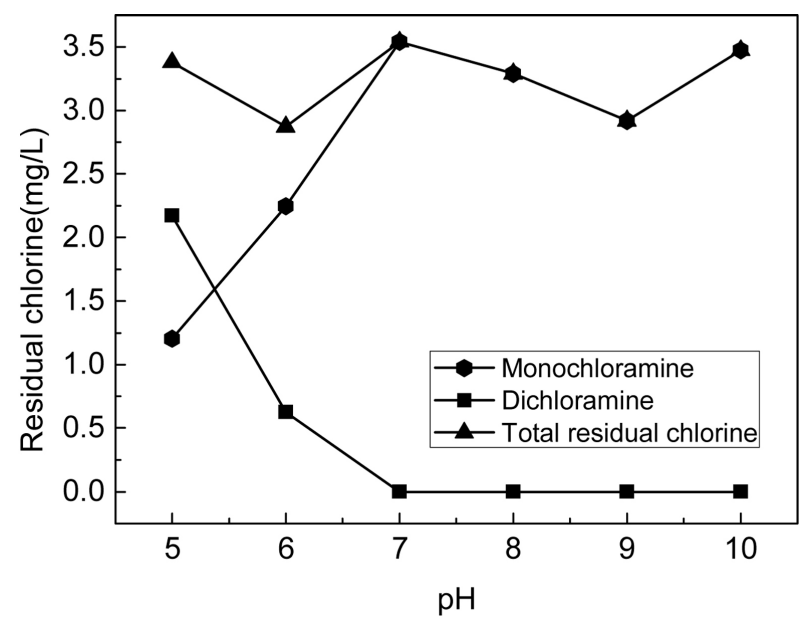

Figure 2. Residual chlorine in different $\mathrm{pH}$.

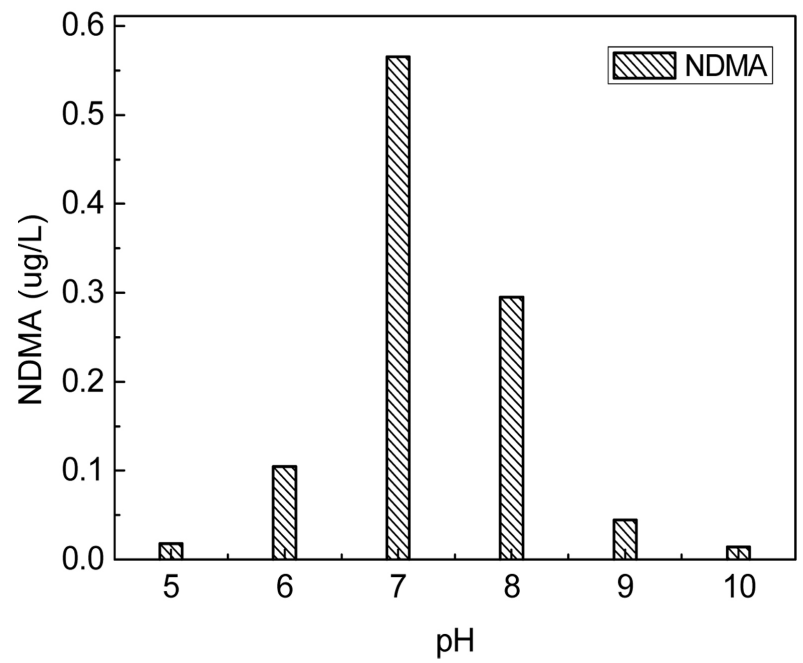

Figure 3. Effect of $\mathrm{pH}$ on NDMA formation.

It can be seen from Figure 4 that when the reaction solution is at $\mathrm{pH}=7$, the concentration of NDMA is the highest, which can reach about $550 \mathrm{ng} / \mathrm{L}$, and the concentration is significantly different from that at other $\mathrm{pH}$; secondly, at $\mathrm{pH}=$ 8 , the concentration of NDMA is $300 \mathrm{ng} / \mathrm{L}$; and the rest are below $100 \mathrm{ng} / \mathrm{L}$. It can be seen from Figure 2 that monochloramine has been produced dichloramine by disproportionation at $\mathrm{pH} 5$ and $\mathrm{pH} 6$. Some scholars have proposed that the reaction of dichloramine and DMA generated NDMA as the main reaction, because the reaction rate is higher than the monochloramine reaction by two orders of magnitude. It can also be found from Figure 3 that the yields at $\mathrm{pH} 5$ and 6 are higher than those at pH 9 and 10. The experimental law is also consistent with the previous literature [10]. The proposed reaction of monochloramine cannot completely explain the amount of NDMA formed in the water. The nucleophilic substitution of secondary amines and dichloramines forms the chlorinated asymmetric dialkyl fluorene intermediate, which is then oxidized by dissolved oxygen or chloramine in water to form NDMA and other unidentified 


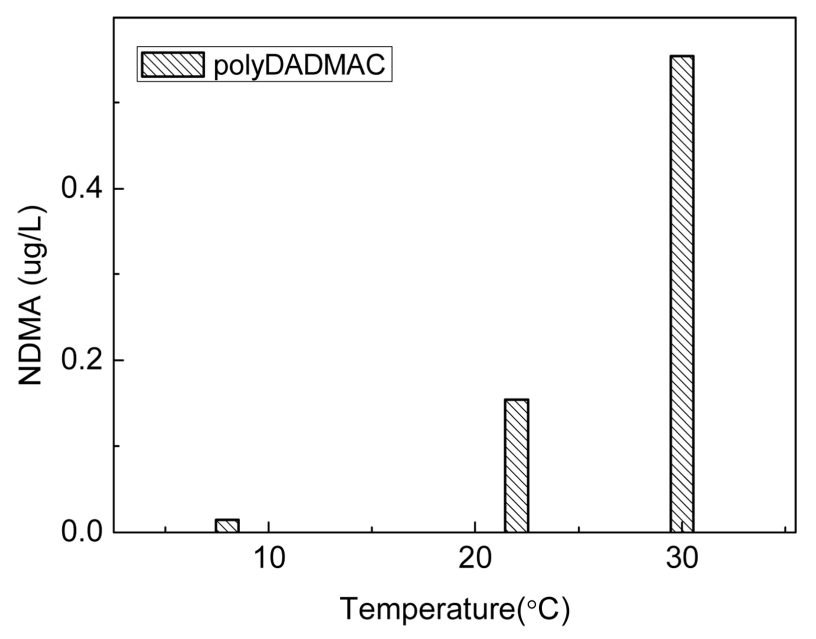

Figure 4. Effect of reaction temperature on NDMA formation.

products. The percentage of unprotonated amine groups in the experiment increased with increasing $\mathrm{pH}$, however, the rapid decay of dichloramine at alkaline $\mathrm{pH}$ led to limited conversion of NDMA; more dichloramine was available at acidic $\mathrm{pH}$, the concentration of non-protonated amine groups is low, NDMA conversion rate is also not high. Eventually, both reach equilibrium at $\mathrm{pH}=7$, and NDMA has the maximum conversion rate. The following experiments are performed at $\mathrm{pH}=7$, so total residual chlorine replaced by monochloramine.

\subsection{Effect of Temperature on NDMA Formation}

It was confirmed that the $\mathrm{pH}$ was $7,10 \mathrm{mg} / \mathrm{L}$ polyDADMAC active ingredient 1 $\mathrm{L}$ and $3.5 \mathrm{mg} / \mathrm{L}$ monochloramine were mixed and chlorinated at the water temperature of $8^{\circ} \mathrm{C}, 22^{\circ} \mathrm{C}$ and $30^{\circ} \mathrm{C}$ for 24 hours in the dark. The effect of temperature on the amount of NDMA generated is shown in Figure 4.

It can be seen from Figure 4 that the yield of NDMA increases with the increase of temperature. On the one hand, the increase in temperature accelerates the reaction rate, on the other hand, concentration of DMA in water increases with increasing polyDADMAC hydrolysis, so that the NDMA formed by chlorination also increases. In contrast, the low temperature reduces the NDMA reaction rate and the hydrolysis of polyDADMAC in water, the resulting NDMA, of course, is also relatively reduced. At the same time, it can be found that the reaction rate of NDMA at a temperature of to $30^{\circ} \mathrm{C}$ is much higher than that of $8^{\circ} \mathrm{C}$ to $22^{\circ} \mathrm{C}$.

\subsection{Effect of Precursor PolyDADMAC Concentration on NDMA Formation}

At $24.0^{\circ} \mathrm{C} \pm 1.0^{\circ} \mathrm{C}, \mathrm{pH}=7.0$, prepare $1 \mathrm{~L}$ of water samples with $2.16,4.32,6.48$, $8.64,10.80 \mathrm{mg} / \mathrm{L}$ active polymer concentration in deionized water, and then reacted with $10 \mathrm{mg} / \mathrm{L}$ monochloramine in the dark for 24 hours. The effect of precursor concentration on NDMA yield in chlorination is shown in Figure 5. 


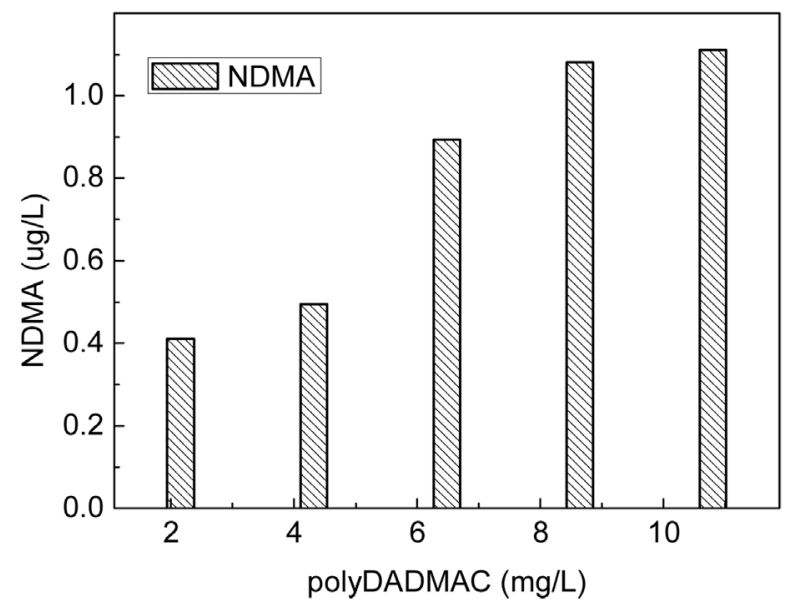

Figure 5. Effect of precursor concentration on NDMA formation.

As can be seen from Figure 5, the concentration of NDMA increased with the increase of precursor concentration. Among them, $2 \mathrm{mg} / \mathrm{L}$ polyDADMAC with $10 \mathrm{mg} / \mathrm{L}$ monochloramine also formed about $400 \mathrm{ng} / \mathrm{L}$ NDMA, while the 10 $\mathrm{mg} / \mathrm{L}$ polyDADMAC with $10 \mathrm{mg} / \mathrm{L}$ monochloramine formed NDMA up to 1000 $\mathrm{ng} / \mathrm{L}$. Therefore, to reduce the risk of large amounts of NDMA formed by chlorination in drinking water system, the concentration of polyDADMAC needs to be controlled during the treatment of flocculation and sedimentation. From Figure 5, it also found that the fastest growth rate of the reaction solution from 4 $\mathrm{mg} / \mathrm{L}$ to $6 \mathrm{mg} / \mathrm{L}$, it shows that the ratio of the concentration of chloramine to the precursor has a great relationship, when the monochloramine concentration is 1.5 - 2.5 times the precursor concentration, the yield of NDMA is higher.

\subsection{Effect of Reaction Time on NDMA Formation and Kinetics}

In the polyDADMAC chlorination experiment, after the effects of the type of chlorinating agent, $\mathrm{pH}$, temperature, and initial concentration of the precursor on NDMA formation have been tested, we continue to study the trend of NDMA concentration with chlorination time. At $24^{\circ} \mathrm{C} \pm 1^{\circ} \mathrm{C}, \mathrm{pH}=7,10 \mathrm{mg} / \mathrm{L}$ polyDADMAC water sample $1 \mathrm{~L}$ with $12 \mathrm{mg} / \mathrm{L}$ monochloramine was reacted in the dark, and samples were taken at $1.5 \mathrm{~h}, 13 \mathrm{~h}, 22 \mathrm{~h}, 49 \mathrm{~h}, 96 \mathrm{~h}$, and $156 \mathrm{~h}$ respectively. The amount of NDMA was formed at different reaction times. The results are shown in Figure 6, the curve of concentration fitting is shown in Figure 7.

As can be seen from Figure 6, it is known that 25\% of NDMA was formed in 24 hours, reaching $1000 \mathrm{ng} / \mathrm{L}$, and then the reaction proceeded, NDMA exceeded $4000 \mathrm{ng} / \mathrm{L}$ at 156 hours. The reaction of precursors with monochloramine formed NDMA is a slow reaction, which explains that the concentration of NDMA in the peripheral water of the pipe network is generally higher than the concentration in the factory water. If the precursors were not removed from the tap water, it will be continuing to form new NDMA with residual chlorine in the 


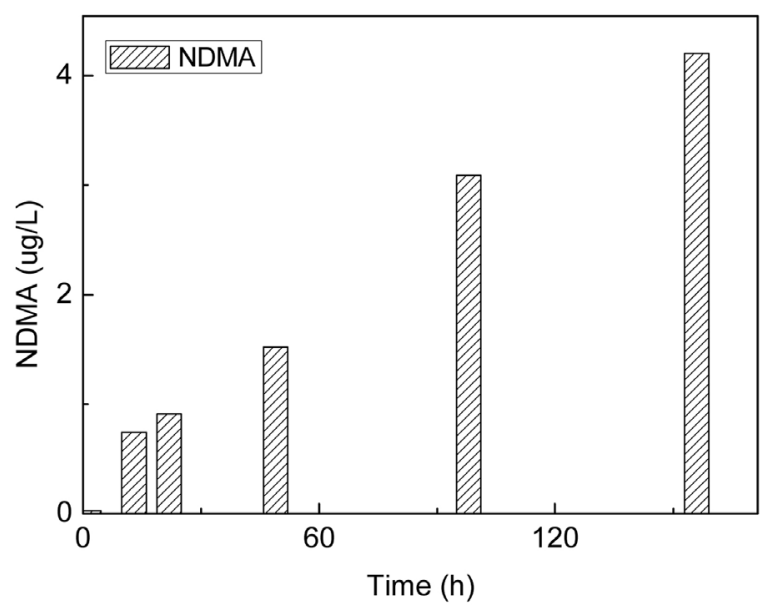

Figure 6. Effect of time on NDMA formation.

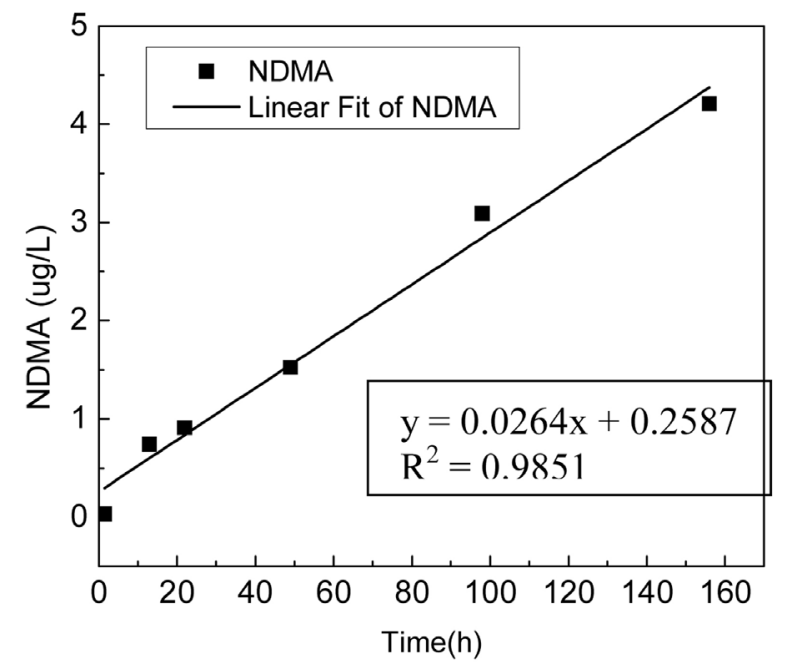

Figure 7. The kinetics of NDMA formation.

pipe network. The kinetic equation for the formation of NDMA by pseudochlorination of polyDADMAC with an excess of monochloramine is shown in Figure 7 as a zero-order reaction.

\section{Conclusions}

Our experimental results show that polyDADMAC has great potential for releasing DMA, and the dimethylamine (-DMA) moiety in polyDADMAC is responsible for the formation of NDMA.

Different chlorinating agent induces different amounts of the formation of NDMA, for example, the yield of NDMA formed by monochloramine is much higher than those formed by sodium hypochlorite.

Under the reacting temperature of $24.0^{\circ} \mathrm{C} \pm 1.0^{\circ} \mathrm{C}$ and solution $\mathrm{pH}$ of 7.0 , the NDMA formation will arrive at the highest efficiency if the monochloroamine concentration was 1.5 - 2.5 times of the substrate concentration.

It is recommended that avoiding direct contact of chloramine with poly- 
DADMAC is efficient to reduce the risk of NDMA formation during water purification. Moreover, it is conducive to reduce the DMA release of polyDADMAC or reduce the risk of NDMA formation by lowering the reaction temperature and inhibiting alkaline $\mathrm{pH}$ of the solution.

\section{Acknowledgements}

This study is funded by the Water Resource Science and Technology Innovation Program of Guangdong Province (2017-27).

\section{Conflicts of Interest}

The authors declare no conflicts of interest regarding the publication of this paper.

\section{References}

[1] Dong, L., Wang, H.Y., Cai, H.q., et al. (2016) Investigation of Status Quo of Nitrogenous Disinfection By-Products in Drinking Water in Six Cities of China. Chinese Journal of Environment and Health, 33, 232-235.

[2] Cal, D. (2011) NDMA and Other Nitrosamines-Drinking Water Issues.

[3] Mitch, W.A. and Sedlak, D.L. (2002) Formation of N-Nitrosodimethylamine (NDMA) from Dimethylamine during Chlorination. Environmental Science \& Technology, 36, 588-595. https://doi.org/10.1021/es010684q

[4] Shah, A.D. and Mitch, W.A. (2011) Halonitroalkanes, Halonitriles, Haloamides, and N-Nitrosamines: A Critical Review of Nitrogenous Disinfection Byproduct Formation Pathways. Environmental Science \& Technology, 46, 119-131. https://doi.org/10.1021/es203312s

[5] Bond, T., Templeton, M.R. and Graham, N. (2012) Precursors of Nitrogenous Disinfection By-Products in Drinking Water: A Critical Review and Analysis. Journal of Hazardous Materials, 235-236, 1-16. https://doi.org/10.1016/j.jhazmat.2012.07.017

[6] Park, S.H., Wei, S., Mizaikoff, B., et al. (2009) Degradation of Amine-Based Water Treatment Polymers during Chloramination as $\mathrm{N}$-Nitrosodimethylamine (NDMA) Precursors. Environmental Science \& Technology, 43, 1360-1366. https://doi.org/10.1021/es802732z

[7] Padhye, L., Luzinova, Y., Cho, M., et al. (2011) PolyDADMAC and Dimethylamine as Precursors of $N$-Nitrosodimethylamine during Ozonation: Reaction Kinetics and Mechanisms. Environmental Science \& Technology, 45, 4353-4359. https://doi.org/10.1021/es104255e

[8] Munch, J.W. and Bassett, M.V. (2004) Method 521, Determination of Nitrosamines in Drinking Water by Solid Phase Extraction and Capillary Column Gas Chromatography with Large Volume Injection and Chemical Ionization Tandem Mass Spectrometry (MS/MS). National Exposure Research Laboratory Office of Research and Development, US Environmental Protection Agency, Cincinnati.

[9] Chen, W., Li, X., Huang, H., et al. (2013) Comparison of Gas Chromatography-Mass Spectrometry and Gas Chromatography-Tandem Mass Spectrometry with Electron Ionization for Determination of N-Nitrosamines in Environmental Water. Chinese Journal of Spectroscopy Laboratory, 168, 1400-1410. 
https://doi.org/10.1016/j.chemosphere.2016.11.109

[10] Shen, R. and Andrews, S.A. (2013) Formation of NDMA from Ranitidine and Sumatriptan: The Role of pH. Water Research, 47, 802-810.

https://doi.org/10.1016/j.watres.2012.11.004 